\title{
Governança federativa nas políticas de saúde e assistência social: processo decisório nas Comissões Intergestores Tripartite (2009-2012)
}

\author{
José Geraldo Leandro \\ Universidade Federal de Minas Gerais (UFMG)
}

Telma Maria Gonçalves Menicucci

Universidade Federal de Minas Gerais (UFMG)

O artigo analisa a produção de decisões intergovernamentais no âmbito das Comissões Intergestores Tripartite das políticas de saúde e assistência social. O pano de fundo é a noção de governança federativa, como forma de governança pública, entendida como as interações intergovernamentais para a busca de melhores resultados das políticas. Foram analisadas atas das reuniões destas comissões no período 2009-2012, sendo comparadas as características das decisões produzidas, os temas e aspectos sobre as quais houve deliberação; tipos de participação por nível de governo; e resultado da deliberação. As conclusões indicam: os padrões da dinâmica intergovernamental são resultado da macro estrutura institucional do Brasil; embora tratem-se de comissões para produção de decisões intergovernamentais não há garantia que todos elementos constitutivos das políticas sejam debatidos e decididos; a garantia institucional de participação dos entes subnacionais não assegura igualdade decisória, embora seu poder de veto e sua influência não possa ser negligenciada.

Palavras-chave: governança, relações intergovenamentais - Brasil, tomada de decisão, política de saúde, assistência social - políticas públicas

[Artigo recebido em 30 de novembro de 2017. Aprovado em 5 de setembro de 2018.] 
Gobernanza federativa en las políticas de salud y asistencia social: proceso decisorio en las Comisiones Intergestores Tripartitas (2009-2012)

El artículo analiza la producción de decisiones intergubernamentales que se producen en las Comisiones Intergestores de las políticas de salud y asistencia social, en que participan los tres niveles de gobierno. La perspectiva de fondo es la noción de gobernanza federativa, como forma de gobernanza pública, entendida como las interacciones intergubernamentales para la búsqueda de mejores resultados de las políticas. Se analizaron actas de las reuniones de estas comisiones en el período 2009-2012, siendo comparadas las características de las decisiones producidas, los temas y aspectos sobre los cuales hubo deliberación; tipos de participación por nivel de gobierno; y el resultado de la deliberación. Las conclusiones indican: los patrones de la dinámica intergubernamental son resultado de la macro estructura institucional de Brasil; aunque se traten de comisiones para la producción de decisiones intergubernamentales no hay garantía de que todos los elementos constitutivos de las políticas sean debatidos y decididos; la garantía institucional de participación de los gobiernos subnacionales no garantiza igualdad decisoria, aunque su poder de veto y su influencia no puede ser descuidada.

Palabras clave: gobernanza, relaciones intergubernamentales - Brasil, toma de decisión, política de salud, asistencia social - reglamentos públicos

\section{Federative governance in health and social assistance policies: decision-making process in Tripartite Inter-managerial Committees (2009-2012)}

The article analyzes the production of intergovernmental decisions that occur in the Intergovernmental Commissions of health and social assistance policies, in which the three levels of government participate. The background is the notion of federative governance, as a form of public governance, understood as intergovernmental interactions that seeks better policies outcomes. Reports meetings of these committees were analyzed in the period 2009-2012, comparing the characteristics of the decisions produced, the themes and aspects on which there was deliberation; types of participation by level of government; and result of deliberation. The conclusions indicate that the patterns of intergovernmental dynamics are the result of the macro institutional structure of Brazil; although they are committees for the production of intergovernmental decisions, there is no guarantee that all elements of the policies will be debated and decided in it; the institutional guarantee of participation of the subnational governments does not guarantee equality of decision power, although its power of veto and its influence should not be neglected.

Keywords: governance, intergovernmental relations - Brazil, decision making, health policy, social assistance - public regulations 


\section{Introdução}

Este artigo parte de um olhar específico sobre a noção de governança, referindo-se à "governança federativa", ou seja, aquela que envolve a participação dos vários entes federados no processo de produção de decisões e de gestão de política públicas, e tem como objeto as políticas de saúde e de assistência social do Brasil.

É lugar comum reconhecer as transformações que vêm sendo operadas na prática governamental nas últimas três décadas, tanto no campo da formulação quanto no da gestão das políticas públicas, e que expressam o entrelaçamento de atores e instituições. A atividade governamental e a produção de políticas públicas se tornaram mais complexas, uma vez que vários atores participam desses processos (PIRES; GOMIDE, 2016, p. 101), o que tem colocado várias demandas para reestruturação das capacidades estatais. Entre essas se ressalta a capacidade de coordenação dos diversos atores, públicos e privados, que participam da produção de serviços públicos, de forma a romper a fragmentação decorrente de processos de descentralização das ações públicas nos vários sentidos que o termo assume, que vão desde a transferência de competências para níveis subnacionais de governo até a delegação de atividades e responsabilidades para setores da sociedade, tanto mercantis quanto não mercantis (MeNICUCCl; GoNTIJO, 2016, p. 16). Nesse contexto de transformações, o tema da governança também se tornou um lugarcomum no debate contemporâneo sobre gestão e políticas públicas, referindo-se às transformações nos processos de governo.

Entretanto, o termo tem sido utilizado de forma heterogênea e com significados distintos. Como chegam a afirmar Kissler e Heidemann (2006, p. 481), "a governança tornou-se um conceito-chave, que todos utilizam sem saber exatamente o que é". Uma característica mais geral de sua utilização se refere à redefinição e ampliação das formas de relacionamento entre o Estado e a sociedade ou entre governo, agentes privados e sociedade, tendo como traço distintivo a dimensão relacional. Como tal, marca uma descentralização do processo decisório e da ação pública para fora dos limites das instituições formais do Estado (KISSLER; HEIDEMAN, 2006, p. 17).

No contexto de reformas da administração pública, no bojo do movimento denominado New Public Management (NPM), governança foi associada à transferência de atividades e funções para agentes privados creditando-se a possibilidade de maior eficácia nesse processo. Noutra vertente, a noção de governança dá ênfase à participação da sociedade nos processos decisórios, perspectiva que se insere em matrizes teóricas da teoria democrática 
contemporânea; nessa perspectiva um adjetivo é agregado ao termo: governança democrática. Qualificada como governança pública, refere-se a interações interinstitucionais para a busca de melhores resultados da atuação governamental, remetendo à ideia de redes de cooperação ente instituições públicas (Silva et al., 2013, p. 250) e envolve dimensões como negociação, comunicação e confiança (FONTES FILHO, 2003, p. 251).

O termo governança aparece também associado à noção de redes de políticas públicas, identificadas como um novo arranjo estrutural na formulação de políticas e que expressam uma descentralização e horizontalização dos processos decisórios, envolvendo não apenas instituições governamentais, mas também agentes privados. ${ }^{1}$ Se as políticas públicas envolvem a conexão entre diversos atores que perpassam fronteiras organizacionais (e territoriais), o conceito de governança pode contribuir para entender esses processos. Em uma síntese, lembramos Sechi (2009, p. 358): “A etiqueta 'governance' denota pluralismo, no sentido que diferentes atores têm, ou deveriam ter, o direito de influenciar a construção das políticas públicas".

Em países federativos, a questão da governança é relevante para entender o processo de formulação e gestão de políticas públicas em função da divisão de poderes que caracteriza esse tipo de regime, e que remete à necessidade de coordenação da ação dos entes federados autônomos e de cooperação entre eles, tanto para a formulação de políticas quanto para sua maior eficácia. Em contextos federativos, uma questão a ser compreendida é como as políticas públicas são equacionadas, negociadas e barganhadas (SouZA, 2016). Como destaca Pierson (1995), as instituições associadas ao federalismo têm implicações para as políticas sociais e, entre outras dinâmicas, geram dilemas associados aos processos decisórios conjuntos decorrentes de a autoridade sobre a elaboração de políticas ser partilhada entre múltiplas jurisdições. Consequentemente, sistemas federais que desenvolvem responsabilidades partilhadas para políticas sociais

\footnotetext{
${ }^{1} \mathrm{~A}$ literatura aponta ainda outros dois outros tipos de perspectivas de gestão e governança: o de mercado e o hierárquico (LOWNDES; SKELCHER, 1998). O primeiro toma emprestado "Os pressupostos básicos das relações contratuais sobre os direitos de propriedade para aplicá-los às relações estatais/governamentais" (GoNTIJO, 2012, p. 85). Em tal perspectiva, os custos e benefícios dos atores envolvidos são entendidos como elementos centrais das relações e, no caso de haver algum conflito entre os envolvidos, a resolução passará pelo debate e tentativa de acordo entre as partes ou por meio do recurso da lei e/ou acesso à justiça, que determinará quais são as responsabilidades dos envolvidos. Essa perspectiva parte do pressuposto de que os mercados possibilitariam um elevado grau de flexibilidade aos atores nas potenciais parcerias ou alianças, mas se tratando sempre de um ambiente bastante competitivo, o que pode limitar o grau de envolvimento dos atores em propostas que pressuponham objetivos compartilhados. Já o modelo hierárquico, em tese superaria os problemas de coordenação e cooperação, presentes tanto nos mercados quanto nas redes, pois a imposição da integração supervisionada por uma estrutura burocrática, com autoridade para tanto, faria com que o cumprimento das normas se tornasse factível, melhorando os níveis de qualidade das ações, embora, com redução da flexibilidade e da criatividade dos atores e tendência à formalização e rotinização dos processos (GoNTIJo, 2012).
} 
específicas tendem a gerar desenhos complexos de política de forma a incorporar as necessidades e interesses de cada ente.

A necessidade de gerir políticas de forma compartilhada pelos entes federados coloca a necessidade de construção de uma "governança federativa", o que demanda concertação política e superação dos conflitos federativos. Do ponto de vista jurídico, ela se expressa na relação de equilíbrio da autonomia dos entes federados e no modus operandi desses atores, com a participação ampla dos componentes federativos, "perpassando institucionalidades, processos decisórios, sistemas administrativos e comunicacionais" (PIRES, 2013, p.167).

No caso brasileiro, ao longo das últimas décadas, dois grandes temas entraram na agenda dos debates e pesquisas acadêmicas, em virtude de sua relevância no período histórico recente: a reconfiguração do sistema federativo a partir da Constituição de 1988 e a descentralização das políticas públicas nesse novo cenário institucional. Esses dois processos inter-relacionados suscitam a reflexão sobre os problemas existentes na interação entre os três níveis de governo, no que diz respeito à gestão e ao financiamento das políticas (ARRETCHE, 2000; 2002a; 2002b; 2003; 2010; 2012; SOUZA, 2001; 2005; ABRUCIO, 2005; MACHAdo, 2008; MENICUCCI, 2014). A Constituição brasileira de 1988 reconfigurou o federalismo do país e definiu um arranjo sui generis com o fortalecimento do ente municipal transformado em ente autônomo da Federação, e reforçou as soluções cooperativas mediante relações diretas entre a União, os estados, os municípios e o Distrito Federal. No caso da maioria das políticas sociais, foram definidas competências comuns que passaram a ser de responsabilidade compartilhada, gerando dificuldades (ou necessidade) de coordenação da ação governamental, remetendo à necessidade de governança compartilhada. No início da década de 1990, iniciou-se um extenso processo de descentralização das políticas nacionais, antes concentradas no nível federal, e diversos mecanismos foram criados para viabilizar as relações federativo-intergovernamentais: a criação de fundos para a execução de transferências financeiras entre os níveis de governos; o estabelecimento de espaços institucionais destinados ao controle social das políticas, como os conselhos constituídos por representantes do Estado e da sociedade civil, nos três níveis de governo; e em algumas políticas deu-se a criação de instâncias destinadas à produção de decisões intergovernamentais.

Entre as estratégias para alinhamento institucional, no caso das políticas de saúde e assistência social, nesta última num processo de isomorfismo com a primeira, foram criados fóruns para coordenação federativa que são as Comissões Intergestores, de âmbito nacional (CIT), estadual (CIB) e regional (no acaso específico da saúde), constituídas por representantes dos entes federados. Tanto 
a CIT quanto a CIB se acercam da ideia de governança federativa, constituindose como arranjos mais descentralizados que envolvem a participação dos entes federados e mecanismos de articulação/coordenação, formando uma governança tripartite em que as responsabilidades são compartilhas entre as três esferas da federação e a ação interdependente entre elas se tornou essencial para a condução das políticas. Podem ser vistas como um arranjo para a produção de políticas públicas que envolve vários atores, proporciona interações entre eles e permite a tomada de decisões pactuadas. Apropriando da definição de governança pública de Richards e Smith (2002), a governança nesse caso provoca a criação de centros múltiplos de elaboração da política pública, em nível regional e nacional. Numa perspectiva relacional e não hierárquica, a alocação de recursos coletivos é definida por meio de relações com vários níveis de governo.

São as Comissões Intergestores Tripartite (CITs), criadas no âmbito das políticas de saúde e assistência social, que se configuram como objeto deste artigo. Essas comissões podem ser definidas como espaços de articulação e interlocução entre representantes dos gestores dos níveis federal, estadual e municipal para viabilizar a execução da política, caracterizando-se como instâncias de negociação e pactuação sobre questões relacionadas à gestão e ao financiamento das ações constitutivas dos setores de saúde e assistência social.

Especificamente, o objetivo é analisar de forma comparada o padrão da produção de decisões intergovernamentais verticais, entre os três níveis de governo, no âmbito das políticas nacionais de saúde e assistência social no Brasil pós-1988, com foco em: (i) estruturas e regras estabelecidas para a produção de decisões conjuntas entre os entes federados, assumindo as Comissões Intergestores Tripartite (CITs) como proxy do processo de produção decisória intergovernamental; (ii) interação entre os atores e as respectivas perspectivas de intervenção; e (iii) dinâmica das relações entre os três níveis de governo em cada setor.

Parte-se da hipótese central de que as políticas nacionais de saúde e assistência social contam com estruturas e regras decisórias formais similares para a produção das decisões conjuntas entre os níveis de governo, mas que, em razão da natureza das políticas e das particularidades dos seus respectivos processos históricos de 
constituição, a produção de decisões tem uma dinâmica diferenciada. ${ }^{2}$ No caso da política de saúde, materializada no Sistema único de Saúde, as decisões relacionadas às suas diferentes áreas de atuação (assistência à saúde, vigilância sanitária, controle epidemiológico e assistência farmacêutica) são produzidas a partir da observância das regras básicas para a construção das decisões intergovernamentais verticais, e a CIT funciona efetivamente como instância decisória para todas as questões pertinentes ao SUS. Por sua vez, no âmbito da política de assistência social, que também se materializa no Sistema Único de Assistência Social, isso não acontece de forma geral, e decisões sobre ações e serviços de origem nacional, especificamente relacionados à garantia de proteção social por meio da transferência de renda, passam às margens da CIT. Embora se reconheça a CIT como arena de pactuação federativa relevante, partimos de uma hipótese adicional apropriada de Arretche (2012), segundo a qual no Brasil pós 1988, o poder decisório sobre as políticas públicas (policy decision-making) continuou concentrado no nível federal de governo, cabendo às subunidades governamentais, na maioria dos casos, o papel de executar as políticas (policy-making), com possibilidades limitadas (embora existentes) de influenciar as decisões sobre as mesmas.

Embora existam outros espaços destinados à coordenação federativa intergestores, como as Comissões Intergestores Bipartite (CIBs) e as recentes

\footnotetext{
${ }^{2}$ Cabe explicitar aqui alguns dos aspectos específicos das duas políticas que podem colocar limites a essa comparação, embora não sejam objeto deste artigo, mas que apontam para diferenças de magnitude entre os recursos, públicos atendidos e serviços prestados. Em primeiro lugar, a política de saúde dispõe de vinculação orçamentária constitucional, que determina o percentual mínimo dos aportes financeiros que devem ser realizados anualmente por cada nível de governo. No caso da assistência social, embora exista uma estrutura institucionalizada de aportes e transferências entre os níveis, o percentual dos recursos destinados depende das disputas relativas ao orçamento público no âmbito de cada ente federado e, apesar do crescimento a partir de 2003, equivalia em 2012 a aproximadamente 1,05\% do PIB, considerando os serviços e os benefícios (IPEA, 2015); no mesmo ano o gasto público com a política de saúde no Brasil atingiu o percentual de 3,9\% do PIB. Em termos de estrutura de atendimento, no mesmo ano, a política de saúde em âmbito nacional contava, por exemplo, considerando apenas a atenção básica, com 34.715 equipes do Programa Saúde da Família, que já havia sido implantado em 96,1\% dos municípios brasileiros e, além disso, a política dispunha de 1,69 leitos/mil habitantes (no âmbito do SUS) e havia realizado até o mês dezembro 2,8 consultas por habitante. Já a política de assistência social, que é focada em públicos específicos, também em 2012, destinou o benefício do Programa Bolsa Família (PBF) a 12,2 milhões de famílias e 3,9 milhões de pessoas eram beneficiárias do Benefício de Prestação Continuada (BPC). O SUAS naquele ano contava com 7.725 Centros de Referência da Assistência Social (CRAS), presentes em 96,9\% dos municípios brasileiros e 2.167 Centros de Referência Especializados de Assistência Social (Creas), instalados no que corresponde a 35,2\% dos municípios brasileiros (os Creas podem ser municipais ou regionais). Nestes dois equipamentos, o público prioritário para o atendimento são os beneficiários do PBF e do BPC, embora haja outros públicos também prioritários e outros segmentos que se encaixam nos critérios de vulnerabilidade que norteiam a política. Embora a assistência tenha se disseminado pelo país, a dimensão da assistência é infinitamente menor do que no caso da atenção à saúde que, em tese, cobre toda a população, da qual, de fato, tem cerca de $75 \%$ de usuários exclusivos, cobrindo também os demais em atendimentos específicos como prevenção e urgência.
} 
Comissões Intergestores Regionais (CIRs) no caso da saúde, a adoção das CITs como proxy dos processos decisórios intergovernamentais no âmbito das duas políticas se justifica pelo fato de se tratarem de instâncias em que os representantes dos três entes federados deliberam conjuntamente sobre as propostas de ações, distribuição de recursos e outras questões pertinentes às respectivas políticas e cujas decisões precisam ser tomadas por consenso entre os representantes dos três níveis de governo, ou seja, não há sobreposição das vontades e interesses pelo recurso majoritário -, o que torna possível captar os reflexos da atuação de cada nível de governo sobre os demais de modo ainda mais complexo. Nosso foco é, assim, sobre as relações e decisões intergovernamentais produzidas a partir da interação entre os três níveis de governo, não sendo consideradas outras instâncias que também fazem parte do arranjo da governança nessas duas políticas, sejam as arenas federativas regionais, como também os conselhos nacionais que são instâncias voltadas ao exercício da participação e controle também por parte da sociedade civil e cujas decisões denotam outra seara de deliberações.

Para esses objetivos, o artigo está estruturado em quatro partes, além desta introdução. Nas duas próximas seções é feita uma síntese sobre a configuração do federalismo e das relações intergovernamentais no Brasil e do arranjo institucional das políticas de saúde e de assistência social, para, em seguida, analisar características da produção decisória no âmbito das Comissões Intergestores Tripartite (CITs) das duas políticas, quando também é descrita a metodologia utilizada para isso. Por fim, são apresentadas algumas conclusões extraídas dessa análise comparativa.

\section{Federalismo e relações intergovernamentais no Brasil}

Como já amplamente difundido, a atual configuração federativa do Brasil é um arranjo modelado ao longo de um extenso e complexo processo, que passou por vários momentos desde o federalismo oligárquico dos primeiros anos republicanos, cuja característica principal foi a substantiva autonomia política e fiscal dos estados governados por elites latifundiárias, passando por uma centralização nos regimes autoritários, até chegar ao estágio contemporâneo que conjuga autonomia dos entes federados e centralização de poder decisório na União (SOUZA, 2001; COSTA, 2003).

Ao longo de tal processo, instituições e práticas federativas que concentravam ou dispersavam autoridades política, fiscal e administrativa foram criadas; algumas passaram por mudanças substantivas nos momentos de inflexão histórica que propiciaram reformas (como na formulação da Constituição Federal de 1988); mas outras foram mantidas, como as que garantem maior força ao governo federal nas relações junto aos estados e municípios. A trajetória das instituições federativas no Brasil teve como consequência esta que é uma das características centrais da 
configuração contemporânea das relações intergovernamentais no país que é a força política e fiscal da União em relação aos governos dos estados e municípios (COSTA, 2003; ARRETCHE, 2010; 2012).

A reconhecida centralização no executivo nacional como característica do federalismo brasileiro significa que há constrangimentos ao exercício da autoridade dos governos sobre suas próprias jurisdições, o que, por outro lado, é uma oportunidade à minimização de desigualdades historicamente constituídas.

Do ponto de vista fiscal, Soares (2012) e Arretche (2012) demonstram existir um conjunto de regulamentações provenientes de legislação federal que implicam constrangimentos à adoção de políticas alternativas ou outras prioridades de gasto pelos municípios. A partir da década de 1990, a autoridade da União sobre estados e municípios tornou-se acentuadamente fortalecida no Brasil quando os mecanismos para a arrecadação de impostos, escolhas na alocação dos recursos, assim como as estratégias e interesses relacionados à implementação de políticas pelas subunidades governamentais tornaram-se ainda mais constrangidos pelos limites impostos pela União (ARRETCHE, 2012, p. 160).

Contudo, em que pese o fato da autoridade tributária dos estados e municípios brasileiros ser condicionada por regras federais que visam à homogeneização e controle, a partir de tais medidas o Governo Federal brasileiro acaba cumprindo um importante papel de redução das desigualdades de receita e, consequentemente, na qualidade das políticas que são ofertadas à população pelas subunidades governamentais. As transferências constitucionais impactam positivamente e de forma substantiva as receitas municipais, sendo a maior fonte de receita da maioria dos municípios; e as transferências condicionadas proporcionam impactos positivos adicionais. A conclusão de Arretche (2012, p. 199) é que no caso brasileiro parece haver "(...) um trade-off entre a redução das desigualdades territoriais e a plena autonomia dos governos locais", cujo fator explicativo principal seriam as regulamentações e supervisões realizadas pelo Governo Federal.

Importa ressaltar que esse trade-off não elimina por completo a autonomia das subunidades governamentais que, em geral, detêm autoridade sobre a execução das políticas (policy-making) e são entes federados politicamente independentes, o que Ihes permitem a discordância ou não adesão às propostas federais (obviamente sob custos de diversas ordens, como o possível não repasse dos recursos) nos casos em que não haja expressa determinação constitucional.

Em relação aos aspectos políticos das instituições federativas brasileiras, a aprovação do conjunto de medidas centralizadoras a partir da década de 1990 só foi possível porque, ao contrário das percepções mais gerais da literatura (RIKER apud ARRETCHE, 2001, p. 27), as instituições políticas pós 1988 no Brasil apresentam 
características que garantem à União amplo poder legislativo sobre assuntos relacionados aos governos subnacionais, conjugado com reduzidas possibilidades de veto por parte destes últimos. Isso porque não há distinção processual para a aprovação de medidas (por parte da União) que afetem os interesses das subunidades governamentais; e ainda, dada a característica de nacionalização partidária, a casa representativa das subunidades apresenta configuração e dinâmica centralmente partidária e não jurisdicional (ARRETCHE, 2012).

Tal configuração traz consequências significativas para as relações verticais entre os níveis governamentais no que diz respeito à gestão compartilhada das políticas públicas (ARRETCHE, 2010; 2012). A Constituição Federal determina muitas áreas de competência da União, o que autoriza o Governo Federal a legislar sobre várias políticas, entre elas a seguridade social, mesmo que sua implementação seja realizada pelos outros níveis de governos. Portanto, em que pese o fato de ter havido descentralização de competências às subunidades governamentais para a execução de políticas, existem dispositivos constitucionais que autorizam o Governo Federal a legislar sobre as mesmas. No geral, os governos subnacionais acabam cumprindo o papel de policy-making (autoridade sobre a execução), ficando as atribuições decisórias principais sobre as políticas (policy decisionmaking) a cargo do Governo Federal. Ainda assim, a autoridade sobre a execução garante às subunidades governamentais o exercício de algum grau de influência sobre as decisões relacionadas às políticas, o que torna as diferenciações e/ou as necessárias variedades de implementação algo factível (ARRETCHE, 2010; 2012).

A seção seguinte descreve o desenho das duas políticas cujas decisões intergovernamentais são analisadas neste artigo, no bojo dessa configuração das relações federativo-intergovernamentais.

\section{Políticas nacionais de saúde e de assistência social}

A política nacional de saúde é prevista pelos artigos 196 aos 200 da Constituição Federal de 1988, que determinam ser a saúde direito de todos e dever do Estado, e sinaliza a criação do Sistema Único de Saúde (SUS), com o objetivo de prestar atendimento à população, por meio da integração dos serviços de assistência à saúde e das ações de vigilância epidemiológica e vigilância sanitária, tendo esta última, entre outras atribuições, a responsabilidade pela fiscalização e controle de um conjunto específico de ações relacionadas ao setor, mas não executadas pelo Estado (como os procedimentos para a produção e comercialização de produtos e substâncias). 
A Constituição estabelece ainda que a política deverá ser executada a partir do compartilhamento de competências entre os três níveis de governo. As atribuições das instâncias governamentais foram delineadas de maneira mais precisa pela Lei no 8.080/90 (LOS) da seguinte forma: à União (Ministério da Saúde) cabe coordenar a política no território nacional, elaborar a agenda nacional de saúde, analisar os planos de saúde, quadro de metas e relatórios de gestão de todos os estados. Assume ainda, junto com os estados e o Distrito Federal, a responsabilidade sobre pacientes referenciados entre estados em atendimentos de alta complexidade que envolvam alta tecnologia, altos custos e integração junto aos outros dois níveis de atenção.

Aos estados (secretarias estaduais de saúde ou equivalente), formalmente, cabe acompanhar, avaliar e controlar as redes hierarquizadas de atenção à saúde que fazem parte de sua região, além de desenvolver ações e ofertar serviços específicos de forma suplementar; cabe a eles também o planejamento do sistema estadual regionalizado e o desenvolvimento de relações cooperativas técnicas e financeiras junto aos municípios.

Aos municípios cabe a elaboração da agenda de saúde, além do plano municipal de saúde, do quadro de metas e dos relatórios de gestão municipal e da programação das ações de saúde municipal. Os órgãos gestores municipais são responsáveis em seus respectivos territórios: (a) pelos serviços de nível básico (conjunto de ações, no âmbito individual e coletivo, que abrangem promoção, proteção, prevenção de agravos, diagnóstico, tratamento, reabilitação e manutenção da saúde); e (b) pelo controle e fiscalização dos prestadores privados. Os municípios que possuem capacidade instalada também são responsáveis por serviços de média e alta complexidade e, de forma cooperativa, devem atender aos outros municípios a partir da construção de redes regionais sob a coordenação estadual.

O Decreto no 7.508/2011, que tardiamente regulamentou a Lei no 8.080/90, tem como foco principal as relações federativas ao buscar assegurar o compromisso dos entes federados com a assistência à saúde integral e de qualidade, e explicita de forma mais clara os conceitos que norteiam a organização da atenção à saúde e reforça as direções desejadas - como a concepção de que a integralidade da assistência se inicia e se completa na Rede de Atenção à Saúde. O sistema possui fóruns institucionalizados de negociação e pactuação intergovernamental que contam com a participação de gestores dos três níveis de governo. Previstas pelas normatizações e em funcionamento no âmbito do SUS, essas arenas de debate e deliberação estão voltadas à dinamização da cooperação entre os entes federados. São elas: as Comissões Intergestores Tripartite (CIT) no âmbito nacional (que prevê a participação de representantes dos gestores das três esferas de governo), a Bipartite (CIB) no âmbito estadual (que prevê a participação de representantes dos 
secretários municipais e estaduais), e mais recentemente, as Comissões Intergestores Regionais (CIR), que são fóruns de coordenação federativa horizontal compostos pelos secretários municipais de saúde das regiões de saúde e por representantes da secretaria estadual de saúde (Lei no 12.466/2011). O Conselho Nacional dos Secretários de Saúde (Conass) e o Conselho Nacional de Secretários Municipais de Saúde (Conasems) são os atores coletivos que representam os gestores estaduais e municipais na CIT, indicando seus representantes. Já as CIBs são constituídas de forma paritária por representantes do governo estadual e do Conselho Estadual de Secretários Municipais de Saúde (COSEMS) de cada estado.

A partir da Lei no 12.466/2011, essas comissões foram reconhecidas como instâncias de decisão do SUS cujas decisões passam a ter validade jurídica, desde que não ultrapassem o seu campo de competência. É reservada a elas a prerrogativa de decidir: (a) sobre os aspectos operacionais, financeiros e administrativos da gestão compartilhada do SUS; e (b) sobre as diretrizes nacionais, regionais e intermunicipais da organização das redes de ações e serviços de saúde. É a partir desses colegiados que os três níveis de governo têm a possibilidade de definir e fixar, conjuntamente, diretrizes nacionais, regionais e intermunicipais relacionadas aos serviços e ações de saúde.

A política de saúde é cofinanciada pelas três esferas de governo, ainda com maior participação do nível federal, e os repasses são realizados a partir do modelo "fundo a fundo" (fundos de saúde dos três níveis de governo). Parte desses recursos são transferências condicionadas e dependem da adesão dos municípios aos programas e objetivos estabelecidos previamente pelo Governo Federal; a maior parte, contudo, é de transferências não condicionadas, embora com regras para o recebimento e a aplicação dos recursos.

Em relação à participação e controle social, a política de saúde prevê a criação de conselhos e a realização de conferências nos três níveis de governo (Lei no 8.142/1990). Os conselhos nacional, estaduais e municipais de saúde visam viabilizar a participação e controle da sociedade sobre a gestão; e as conferências nacionais, estaduais e municipais de saúde são espaços de participação voltados para a definição das diretrizes que orientam a política. Dessa forma, a configuração institucional da política de saúde dispõe tanto de instâncias de articulação e deliberação entre os gestores dos distintos níveis governamentais, quanto de espaços colegiados de participação da sociedade, também nos três níveis de governo (MENICUCCI, 2014).

Em síntese, o SUS foi criado como um pacto federativo assentado em uma concepção de cooperação entre as três esferas de governo. Isso é um imperativo pela própria natureza da atenção à saúde que demanda a gestão de uma rede 
de serviços diversificada e distribuída em diferentes níveis de complexidade, em geral territorialmente dispersa e atuando em escalas variadas em função do grau de complexidade e da demanda, o que configura a chamada hierarquização da atenção. Isso coloca a necessidade de combinar a autonomia dos entes federados e a cooperação entre eles de forma a garantir a universalidade e a integralidade da atenção, compatibilizando a localização territorial das pessoas com a da rede assistencial sob a responsabilidade de gestores de diferentes unidades territoriais Nesse arranjo cooperativo, o Governo Federal ocupa posição central, pois detém o controle do processo decisório, define o formato da cooperação e a destinação dos recursos transferidos; enquanto os municípios são os executores e gestores dessa política (ARRETCHE, 2012; MENICUCCI, 2014; VIANA, et. al. 2002). Mecanismos como as comissões intergestores foram estabelecidos no intuito de favorecer as relações concertadas necessárias ao desenvolvimento da política.

A partir de 1988, a assistência social passa a ser prevista constitucionalmente (CF1988/art. 203) e a compor, junto com a saúde e a previdência social, o conjunto de ações e iniciativas do Estado brasileiro denominado seguridade social. A política de assistência social, de acordo com a Constituição, é direito do cidadão e destinada a quem dela necessitar, independente de contribuição à seguridade social, e tem como objetivos principais: a proteção à família, à criança, ao adolescente, ao idoso e à pessoa com deficiência, com vistas à integração ou reintegração à vida comunitária, além da promoção da integração ao mercado de trabalho.

Essa política tem como bases legais fundamentais, além da Constituição, a Lei no 8.742/93 (Lei Orgânica da Assistência Social - LOAS) e a Lei no 12.435/2011, que a modifica; a Resolução no 145 (CNAS), de 15 de Outubro de 2004, que estabelece a Política Nacional de Assistência Social (PNAS) e o Sistema Único de Assistência Social, as NOBs/SUAS 2005 e 2012 (Normas Operacionais Básicas), além dos estatutos da criança e do adolescente (Lei no 8.069/1990) e do estatuto do idoso (Lei no 10.741/2003), que não são específicos à política de assistência, mas delineiam ações junto a tais públicos em seu âmbito. Apesar da existência de atendimentos específicos aos distintos segmentos populacionais, a PNAS/Suas tem como orientação central a matricialidade sócio-familiar na perspectiva de ter a família e suas vicissitudes contemporâneas como foco das intervenções.

As normatizações dividem a atuação da assistência social em dois blocos, que operam a partir de uma série de programas e projetos que se pretendem como um sistema: a Proteção Social Básica (PSB) e a Proteção Social Especial (PSE). A primeira é voltada à prevenção das situações de risco, por meio do fortalecimento dos vínculos familiares e comunitários em territórios geográficos delimitados a 
partir de indicadores socioeconômicos (ações de baixa complexidade); e a segunda, ao atendimento de famílias ou indivíduos com direitos violados ou em situação de risco (média e alta complexidade). A política prevê dois equipamentos de base local a serem implantados nos territórios delimitados por cada bloco de atuação, os CRAS (Centros de Referência da Assistência Social) para a Proteção Social Básica e os Creas (Centro de Referência Especializado da Assistência Social) para a Proteção Social Especial. Além dos serviços, a política prevê como mecanismos de proteção social por meio da renda: o Benefício de Prestação Continuada (BPC) e a transferência de renda por meio de programas que repassem recursos diretamente aos beneficiários, visando ao combate à fome, à pobreza e outras formas de privação de direitos que levem à situação de vulnerabilidade social (NOB/Suas 2005 e 2012); ambos compõem o nível de proteção social básica.

Assim como no caso da saúde, as normatizações da assistência social também estabelecem mecanismos voltados à participação e ao exercício de deliberação conjunta entre os gestores dos três níveis de governo: as Comissões Intergestores Tripartite ( $\mathrm{CIT}$ ) no âmbito nacional, e Bipartite ( $\mathrm{CIBS}$ ), no âmbito estadual. Além da existência do Fórum Nacional de Secretários de Estado da Assistência Social (Fonseas), do Colegiado Nacional de Gestores Municipais de Assistência Social (Congemas) e do Colegiado Estadual de Gestores Municipais de Assistência Social (Coegemas), que são as entidades representativas dos gestores municipais e estaduais da política, responsáveis pela indicação dos membros que compõem as comissões intergestores. Essas são definidas como um espaço de articulação e interlocução entre os gestores dos três níveis de governo para viabilizar a política de assistência social, e instância de negociação e pactuação (NOB/Suas 2012, art. 134).

Compete à CIT, entre outras atribuições: pactuar estratégias e estabelecer acordos para a implantação, a operacionalização e o aprimoramento do SUAS; pactuar instrumentos, parâmetros e mecanismos de implementação e regulamentação; pactuar critérios de partilha e procedimentos de transferências de recursos para o cofinanciamento de serviços, programas, projetos e benefícios para os estados e municípios.

Assim como a política de saúde, o campo da assistência social também estabeleceu espaços institucionais formais destinados ao controle e à participação social, determinando a criação de conselhos e a realização de conferências nos três níveis de governo (CF1988; PNAS/2004; NOB/Suas/2005). As conferências são mecanismos formais que viabilizam a participação da sociedade na definição das diretrizes que orientam a política. Já os conselhos têm como principais atribuições a deliberação e a fiscalização da execução da política e seu financiamento, em 
consonância com as diretrizes elaboradas nas conferências; apreciação e aprovação da proposta orçamentária e do plano de aplicação do fundo da assistência social; e da incumbência de normatizar, disciplinar, acompanhar, avaliar e fiscalizar os serviços de assistência social.

O sistema é cofinanciado pelas três esferas de governo, com maior participação do nível federal, e a transferência de recursos também adota o sistema "Fundo a Fundo". Aqui também existem pisos distintos que definem regras gerais para as transferências e aplicação dos recursos; e condicionalidades específicas para os repasses destinados ao tratamento de aspectos particulares das distintas localidades. (NOB/Suas, 2012).

Além dessas semelhanças, resguardadas as respectivas naturezas das duas políticas, os objetivos da constituição do Suas são semelhantes aos do SUS. Ambos visam ao estabelecimento de competências compartilhadas e responsabilidades específicas similares entre as esferas de governo; a universalização do acesso a partir da criação de redes e serviços descentralizados e hierarquizados. Específica e similarmente, são objetivos do Suas: consolidar a gestão compartilhada, o cofinanciamento e a cooperação técnica entre todos os entes federados; estabelecer as suas responsabilidades na organização, regulação, manutenção e expansão das ações de assistência social; orientar-se pelo princípio da unidade e regularidade, em todo o território nacional (NOB/Suas, 2012).

Sobre as responsabilidades dos entes federados, cabe à União, entre outras, regulamentar e cofinanciar, por meio de transferência regulamentar e automática, o aprimoramento da gestão dos serviços, programas e projetos de proteção social básica e especial; regular o acesso às seguranças de proteção social; realizar o monitoramento e a avaliação da política de assistência social e assessorar os estados, o Distrito Federal e os municípios para o seu desenvolvimento; apoiar técnica e financeiramente os estados, o Distrito Federal e os municípios na implementação; responder pela concessão e manutenção do Benefício de Prestação Continuada (BPC); coordenar em nível nacional o Cadastro Único e o Programa Bolsa Família (NOB/Suas, 2012).

Aos estados cabe, além do cofinanciamento da política por meio de transferências aos entes municipais, entre outras atribuições: estimular e apoiar técnica e financeiramente as associações e consórcios municipais na prestação de serviços de assistência social; organizar, coordenar e prestar serviços regionalizados da proteção social especial de média e alta complexidade; realizar o monitoramento e a avaliação da política de assistência social em sua esfera de abrangência e assessorar os municípios para seu desenvolvimento; e apoiar técnica e financeiramente os municípios para a implantação e gestão do Suas, do 
Cadastro Único e do Programa Bolsa Família (NOB/Suas, 2012). Os municípios são corresponsáveis pelo financiamento e são os executores das ações da Proteção Social Básica e Especial em suas respectivas jurisdições, além de realizarem a gestão local do BPC, do Cadastro Único e das características cabíveis do Programa Bolsa Família.

A breve descrição das duas políticas aponta para semelhanças em relação ao desenho institucional, tanto no que diz respeito à organização do atendimento voltado à população quanto em relação à estrutura formal estabelecida para pactuações e decisões conjuntas entre entes federados. Contudo, embora o arranjo institucional das duas políticas garanta participação dos gestores das três esferas de governo em instâncias decisórias compartilhadas, o nível federal é o ator principal na formulação, regulação e coordenação das ações intergovernamentais. Em ambas as políticas, o governo nacional possui recursos institucionais para influenciar as decisões dos governos subnacionais, particularmente a autoridade constitucional de definir as normas nacionais e o maior poder de gasto que lhe permite o controle sobre as ações que serão implementadas pelos estados e municípios. A grande dependência financeira dos municípios na relação com o Governo Federal Ihes garante a autoridade (em graus variados) sobre a execução das políticas, sendo a autoridade decisória preponderantemente do nível federal.

Mas, as duas políticas têm trajetórias históricas de constituição distintas em vários aspectos, variações que têm impacto sobre as características da dinâmica decisória intergovernamental de cada setor, expressas na atuação das comissões intergestores tripartite, tratada a seguir.

\section{As características da produção decisória no âmbito das Comissões Intergestores Tripartite (CITs) das políticas de saúde e assistência social}

Para atender ao objetivo de analisar o padrão da produção de decisões intergovernamentais verticais, entre os três níveis de governo, no âmbito das políticas nacionais de saúde e assistência social no Brasil pós-1988, foram analisadas as atas das reuniões das respectivas CIT. Foram pesquisadas 71 atas de reuniões realizadas entre fevereiro de 2009 e dezembro de 2012, sendo 31 da CIT da política de assistência social e 40 da CIT da política de saúde.

O recorte temporal adotado levou em consideração o período de maturação e revisão institucional da Política Nacional de Assistência Social e do Sistema Único de Assistência Social, instituídos e normatizados em 2004 e 2005, respectivamente. Entre 2009 e 2012 três normas foram produzidas com a finalidade de revisão e avanço institucional: a Tipificação Nacional de Serviços 
Socioassistenciais e o Protocolo de Gestão Integrada de Serviços, Benefícios e Transferências de Renda no âmbito do Suas, ambos de 2009; e a NOB/Suas 2012, também deliberada na CIT e aprovada pelo Conselho Nacional de Assistência Social (Resolução no 33/2012). Por meio desses documentos, a política objetivou ascender a um novo patamar de estruturação e institucionalidade (BRASIL, 2012).

A adoção do mesmo recorte temporal para o campo da saúde decorre da necessidade de comparabilidade, além de manter constante o contexto governamental, embora as primeirasnormatizaçõesemovimentos deimplementação do SUS tenham ocorrido bem antes, mas em outra conjuntura econômica, política e institucional. Ainda assim, o período entre 2009 e 2012 no campo da saúde também é marcado por importantes decisões provenientes de novos esforços de consolidação de alguns dos aspectos centrais das relações intergovernamentais/ federativas, como aquelas impulsionadas pelo Decreto Presidencial no 7.580/2011, cujos dispositivos visam assegurar o compromisso dos entes federados com a assistência à saúde integral e de qualidade, reforçando uma gestão compartilhada entre eles, e a Lei no 12.466/2011, que dá maior institucionalidade às comissões intergestores, enquanto espaços de coordenação federativa no âmbito do SUS, e cria as Comissões Intergestores Regionais (CIR) (MENICUCCI, 2014). Ou seja, no caso da saúde, o recorte temporal adotado é também pertinente no que diz respeito aos processos que envolvem as decisões intergovernamentais.

A organização das informações das atas foi desenvolvida da seguinte forma: inicialmente foi feita uma primeira leitura e, concomitantemente, a organização textual (por trechos) do conteúdo, que foi distribuído entre os seguintes aspectos: temas sobre os quais houve deliberação, classificados de acordo com aspectos estruturantes específicos de cada política; aspecto tratado dentro do tema (gestão, financiamento e aspectos políticos); tipos de participação por nível de governo; e decisão tomada (resultado da deliberação). A partir dessa classificação, foi feita a codificação e contabilização das informações. O Quadro seguinte descreve os temas e aspectos considerados. 
Quadro 01 - Temas e aspectos considerados para a classificação das informações contidas nas atas das CITs

\begin{tabular}{|l|l|}
\hline Assistência Social & Saúde \\
\hline & Tema sob deliberação \\
\hline Tema sob deliberação & - Assistência à saúde \\
- Bolsa Família; & - Vigilância sanitária \\
- Benefício de Prestação Continuada & - Controle epidemiológico \\
- Serviços de Assistência Social & - Assistência farmacêutica \\
- Rede Assistencial Privada & - Setor suplementar \\
Aspecto do tema sob deliberação & - Outros \\
- Gestão administrativa & Aspecto do tema sob deliberação \\
- Financiamento & - Gestão administrativa \\
- Questões políticas & - Financiamento \\
Tipo de Participação dos Níveis de & - Questões políticas \\
Governo & Tipo de Participação dos Níveis de \\
- Propôs a matéria & Governo \\
- Apresentou Concordância & - Propôs a matéria \\
- Apresentou destaque/discordância & - Apresentou Concordância \\
- Posicionou-se neutro & - Apresentou destaque/discordância \\
Resultado da Deliberação & - Posicionou-se neutro \\
- Pactuado como proposto & Resultado da Deliberação \\
- Pactuado com adequações & - Pactuado como proposto \\
- Rejeitado & - Pactuado com adequações \\
- Inconcluso & Rejeitado \\
\hline
\end{tabular}

Fonte: elaboração própria

\section{A política de assistência social}

A Tabela seguinte mostra os resultados gerais da produção decisória da CIT da Assistência Social no período analisado. 
Tabela 01 - Deliberações por temas nas reuniões da Comissão Intergestores Tripartite da Política de Assistência Social (2009-2012).

\begin{tabular}{lcccccccc}
\hline Temas & No & $\%$ & $\begin{array}{c}\text { Aspectos } \\
\text { Gestão }\end{array}$ & $\%$ & $\begin{array}{c}\text { Aspectos } \\
\text { Financ. }\end{array}$ & $\%$ & $\begin{array}{c}\text { Aspectos } \\
\text { Políticos }\end{array}$ & $\%$ \\
\hline $\begin{array}{l}\text { Serv. } \\
\text { Assist. Soc. }\end{array}$ & 118 & 85,51 & 94 & 79,66 & 21 & 17,80 & 3 & 2,54 \\
\hline $\begin{array}{l}\text { Bolsa } \\
\text { Família }\end{array}$ & 13 & 9,42 & 13 & 100 & 0 & 0 & 0 & 0 \\
\hline BPC & 4 & 2,90 & 4 & 100 & 0 & 0 & 0 & 0 \\
\hline $\begin{array}{l}\text { Rede } \\
\text { Privada }\end{array}$ & 3 & 2,17 & 3 & 100 & 0 & 0 & 0 & 0 \\
\hline \begin{tabular}{l} 
Total \\
\hline
\end{tabular} & 138 & 100 & $\begin{array}{c}114 \\
(82,60 \%)\end{array}$ & - & $\begin{array}{c}21 \\
(15,21 \%)\end{array}$ & - & $\begin{array}{c}3 \\
(2,19 \%)\end{array}$ & - \\
\hline
\end{tabular}

Fonte: elaboração própria a partir das atas da CIT da Política de Assistência Social (2009-2012).

Constata-se que $82,60 \%$ das deliberações são referentes às questões de gestão administrativa das ações estruturantes do campo; havendo, apenas no que diz respeito aos serviços de assistência social, 15,21\% de deliberações sobre aspectos relacionados ao financiamento e 2,19\% de deliberações sobre questões de cunho político. As deliberações relacionadas ao Programa Bolsa Família, ao BPC e à Rede Assistencial Privado-filantrópica são exclusivamente relacionadas à gestão. Isso sugere que a CIT da Assistência Social é uma instância de deliberação intergovernamental em que se decide muito pouco sobre aspectos relacionados ao financiamento e às questões políticas do setor.

A distribuição percentual das deliberações é fortemente desequilibrada, com acentuada concentração de decisões sobre os Serviços de Assistência Social, que somam $85,51 \%$ do total. As deliberações sobre as outras ações estruturantes do campo somam juntas menos de $15 \%$ do total, com a informação adicional de que, nos casos do PBF e do BPC, $47 \%$ dessas deliberações ocorreram durante a elaboração do Protocolo de Gestão Integrada de Serviços e Benefícios, empreendido pelos atores ligados ao Suas, como uma tentativa de viabilizar alguma aproximação e ingerência sobre os benefícios de renda, principalmente sobre o PBF. Uma estratégia de pouco sucesso, dado que as informações sobre os anos posteriores demonstram que as decisões sobre o Programa Bolsa Família e o BPC no âmbito da CIT continuaram sendo infimamente frequentes.

Aspectos da trajetória histórica da política apontam que a consolidação dos Serviços de Assistência Social e a criação do SUAS foram encabeçados por atores distintos daqueles que tiveram como proposta principal a transferência de renda como forma de proteção social. Do ponto de vista institucional, as propostas de 
intervenção referentes à proteção social por meio da renda (benefícios) seguiram caminhos específicos no âmbito da política; de um lado configurou-se o BPC, um benefício que compõe a Política de Assistência Social, mas é executado e controlado financeiramente pela Previdência Social; e do outro, foram criados os diversos benefícios de transferência de renda que, posteriormente, se transformaram no PBF. No processo de criação do Ministério de Desenvolvimento Social, estruturas institucionais previamente existentes, responsáveis pelo Programa Bolsa Família e pelos Serviços de Assistência Social (entre outras), passaram a compor o ministério, mas com autonomia em relação às demais e especificidades de intervenção asseguradas. Embora tenha havido esforços de integração das ações, a estrutura organizacional formalizada por meio da criação de secretarias dotadas de responsabilidades particulares acabou prevalecendo. A forte concentração das deliberações sobre aspectos relacionados aos Serviços de Assistência Social no âmbito da CIT expressa a inclusão tardia e relativamente conflitiva dos benefícios de transferência de renda no escopo da política de assistência social, além de se tratar de um programa definido nacionalmente com participação secundária dos entes federados na sua gestão. Pode se supor que, neste caso, a estrutura de governança aponta menos para uma governança pública federativa, coordenada e horizontalizada, mas para uma estrutura hierárquica em que o nível nacional toma as decisões e define a forma de implementação e as instituições responsáveis por ela, com pouca margem para participação dos entes federados. Isso leva a uma implementação considerada exitosa não tanto pela coordenação hierárquica, mas pela relativa simplicidade do programa de transferência de renda, que não exige adaptações e flexibilidade no momento da implementação e nem mesmo um papel ativo do usuário como no caso dos serviços assistenciais que apostam no seu empoderamento e adesão.

O Gráfico 01 a seguir aponta o padrão de participação dos entes federados no âmbito da CIT. 


\section{Gráfico 01 - Tipos de participação (\%) de cada nível de governo nas deliberações na CIT da Política de Assistência Social (2009-2012)}

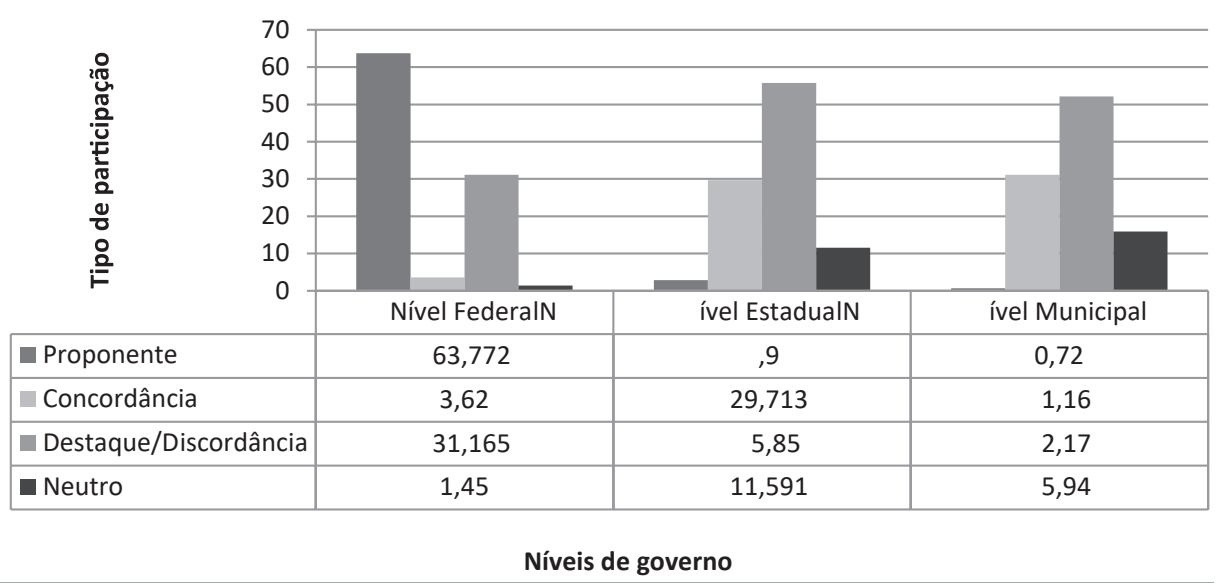

Fonte: Organizado pelos autores a partir das atas da CIT) da Política de Assistência Social (2009-2012).

Em relação à participação do nível federal, o principal tipo de participação é a proposição de matérias para deliberação, havendo também um considerável percentual de intervenções voltadas a explicitar adequações e mudanças necessárias (destaques), ou à discordância em relação a traços específicos das propostas deliberadas. No caso das características de participação dos representantes dos níveis estadual e municipal de governo, as informações das atas demonstraram existir um padrão que conjuga o endossamento das matérias propostas, na maioria pelo nível federal, com a apresentação de destaques sobre adequações e discordâncias referentes às matérias - esta última se constituindo como a principal característica da participação desses entes que, mesmo sendo pouco propositivos, não são passivos.

Além de exercer, quase que de forma exclusiva, a função de ser o proponente das matérias sob deliberação, o nível federal também tem atuação considerável como elaborador e revisor das decisões pactuadas. Estados e municípios exercem de forma compartilhada com o nível federal a função de veto e ou adequação das matérias postas em debate. Esse padrão de distribuição das funções participativas nas deliberações da CIT expressa o poder do nível federal na relação com as subunidades governamentais, que conjuga a descentralização - de forma que estados e municípios não são entes passivos - com concentração de poder no âmbito federal. Esse padrão das relações entre os níveis de governo, identificados no âmbito da CIT, é expressão e desdobramento das características macro institucionais brasileiras que favorecem a concentração de poderes no nível federal. 
O Gráfico 02 também ilustra o argumento de que o padrão das interações entre os níveis de governo tem como características centrais a predominância do nível federal na relação com as subunidades governamentais, mas também a atuação destas últimas no sentido de apresentar destaques às proposições, demonstrando considerável influência sobre as decisões.

Gráfico 02 - Resultados (\%) das deliberações em geral e quando o nível federal atuou como proponente nas reuniões da CIT da Política de Assistência Social (2009-2012)

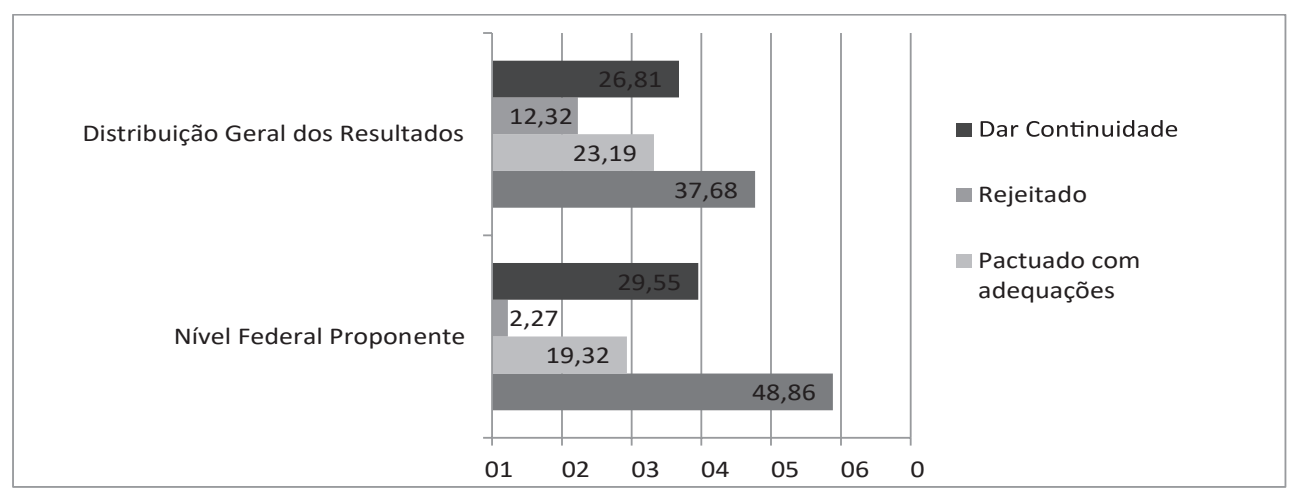

Fonte: elaboração própria a partir das atas da CIT da Política de Assistência Social (2009-2012).

A distribuição geral dos resultados das deliberações apresenta maior percentual de pactuações das matérias tal como propostas, ou seja, sem haver destaques $(37,68 \%)$, mas também um percentual considerável de pactuações após ajustes e adequações e de rejeições, que juntas somam 35,51\% do total. Quando verificamos especificamente os resultados das deliberações nas situações em que o nível federal foi o proponente, encontramos um padrão de distribuição semelhante, embora com aumento percentual das matérias pactuadas da forma como foram propostas e uma queda de $10,05 \%$ das matérias rejeitadas. Dado que o número de matérias pactuadas sem adequações nas duas situações analisadas é predominante e que quase a totalidade das mesmas $(94,62 \%)$ foram apresentadas pelo nível federal, o argumento de haver maior poder de influência deste nível na produção das decisões torna-se ainda mais explícito e convincente.

As deliberações pela continuidade dos debates também são mais favoráveis aos propósitos do nível federal de aprovar suas propostas da forma como foram elaboradas. A análise das atas possibilita perceber que, em 45,95\% das situações em que se optou por tal decisão não houve acordo entre os entes ou se percebeu a necessidade de aprofundamento da discussão; contudo, nos 54,05\% restantes houve alinhamento das subunidades federadas quanto ao não endossamento das matérias apresentadas pelo nível federal e em relação ao encaminhamento a ser adotado. As propostas não foram aprovadas com adequações e nem rejeitadas, 
mas tiveram a decisão adiada, não atendendo às posições de momento dos representantes das subunidades governamentais, reforçando a compreensão sobre a força do nível federal.

Ao mesmo tempo, fica também evidente haver um papel ativo de intervenção das subunidades governamentais no processo deliberativo, que juntas foram responsáveis por $77,60 \%$ (40,10\% dos representantes estaduais e 37,50\% dos municipais) das apresentações de destaques e discordância, com percentual razoável de sucesso das suas intervenções, o que é verificado pela soma dos percentuais de pactuações com adequações e de rejeições às propostas, ambas objetivos das intervenções principais desses dois níveis de governo.

Em síntese, o padrão decisório no âmbito da CIT da assistência social apresenta como características centrais, por um lado, a alta concentração de deliberações sobre temas relacionados aos serviços de assistencial social, em contraposição àquelasreferentes aos benefícios de renda e às questões relacionadas à rede assistencial privado-filantrópica. E por outro, há considerável força do nível federal de governo na relação com as subunidades governamentais, ainda que as possibilidades de participação e influência dessas últimas sobre as decisões precisem ser consideradas no jogo decisório.

\section{A política de saúde}

No caso da saúde, as atas demonstraram haver ampla predominância de deliberações sobre aspectos referentes à assistência à saúde, quando comparados às demais ações integrantes do SUS. A dinâmica da CIT, durante o período analisado, foi impactada (principalmente no ano de 2011, mas também em 2012) pelo Decreto Presidencial no 7.580/2011, que fez aumentar a quantidade de matérias deliberadas sobre os serviços de urgência e emergência e sobre a saúde materno-infantil em função da criação das redes temáticas de atenção à saúde, uma determinação do Decreto, o que, consequentemente, aumentou o número de deliberações relacionadas à assistência à saúde. Mas independentemente disso, há uma tendência geral durante o período, de maior concentração das deliberações sobre tal aspecto. Em 2009 registram-se 44 deliberações sobre assistência à saúde (84,61\% do total); em 2010, 37 (61,66\%); em 2011, 74 $(76,28 \%)$, com alta concentração sobre os temas mencionados; e em 2012, 45 deliberações, 69,23\% do total. 
Tabela 02 - Deliberações por temas (\%) nas reuniões da CIT da Política de Saúde (2009-2012).

\begin{tabular}{lcccccccc}
\hline Temas Discutidos & No & $\%$ & $\begin{array}{c}\text { Aspectos } \\
\text { Gestão }\end{array}$ & $\%$ & $\begin{array}{c}\text { Aspectos } \\
\text { Financ. }\end{array}$ & $\%$ & $\begin{array}{c}\text { Aspectos } \\
\text { Políticos }\end{array}$ & $\%$ \\
\hline Assist. Saúde & 200 & 72,99 & 130 & 65 & 68 & 34 & 2 & 1 \\
\hline Vig. Sanitária & 20 & 7,30 & 4 & 20 & 15 & 75 & 1 & 5 \\
\hline Cont. Epidemiol. & 24 & 8,76 & 8 & 33,33 & 16 & 66,67 & 0 & 0 \\
\hline Assist. Farmac. & 15 & 5,47 & 10 & 66,67 & 5 & 33,33 & 0 & 0 \\
\hline Setor Suplementar & 2 & 0,73 & 2 & 100 & 0 & 0 & 0 & 0 \\
\hline Outros & 13 & 4,74 & 11 & 84,62 & 2 & 15,38 & 0 & 0 \\
\hline Total & 274 & 100 & 163 & - & 108 & - & 3 & - \\
\hline
\end{tabular}

Fonte: elaboração própria a partir das atas da CIT da Política de Saúde (2009-2012).

Se nas duas políticas há predominância de decisões relativas ao tema relativo aos serviços propriamente ditos (serviços na assistência social e assistência à saúde na política de saúde), há uma diferença importante entre as duas em relação aos outros temas. Ao passo que na CIT da Assistência Social todas as ínfimas decisões sobre temas minoritários - o PBF e o BPC - eram relacionadas a aspectos de gestão (parte no bojo do Protocolo de Gestão Integrada de Serviços e Benefícios e outra parte referente à função de acompanhamento e execução de ações junto às famílias beneficiadas), na CIT da Saúde as decisões sobre outros temas minoritários, especificamente o controle epidemiológico e a vigilância sanitária, referem-se a aspectos estruturantes para o funcionamento dessas ações, envolvendo as características dos equipamentos (como laboratórios), estratégias e insumos para as intervenções, referentes tanto à gestão quanto ao financiamento (liberação ou não dos recursos disponíveis e a forma de aplicá-los).

Entretanto, a desproporcional atenção dada aos aspectos da assistência à saúde sugere a ainda baixa integração entre as ações que compõem o SUS (ações coletivas e assistência médica), expressando a centralidade das ações assistenciais durante a trajetória histórica da política, em que pesem inúmeros avanços após a Constituição de 1988. O foco principal no processo de implantação do SUS foi a igualdade de acesso às ações e serviços de saúde, entendido como o direito à atenção à saúde em qualquer espaço geográfico do país. Ou seja, a universalidade e a igualdade no acesso as ações e serviços (MENICUCCI; D’AlBUQUERQUE, 2018). Isso se traduz no maior gasto com assistência e permite entender a prioridade dos temas nas decisões da CIT. Além disso, é na assistência à saúde que o estabelecimento de estratégias de gestão envolvendo os três níveis de governo é crucial para a viabilidade da assistência de forma universal e integral para todos os cidadãos. Isso 
demanda a construção de redes de atenção que extrapolam os limites territoriais dos municípios e exige a cooperação entre os entes federados. Enquanto uma arena federativa, a CIT pode ser crucial par a construção de pactos nesse sentido.

Embora as deliberações referentes aos aspectos de gestão também sejam predominantes na CIT saúde (59,5\% do total), as decisões referentes ao financiamento são significativas, alcançando $39,41 \%$ do total, o que marca uma explícita diferença em relação à CIT da Assistência Social. Isso expressa a centralidade do debate sobre a insuficiência dos recursos e sobre a definição dos fluxos financeiros no âmbito da saúde, no qual reconhecidamente há um problema crônico de subfinanciamento que tem inviabilizado a efetivação de um sistema universal tal como previsto na constituição. Para além disso, existem dispositivos legais - art. 32 do Decreto no 7.508/2011³ e art. 14-A da Lei no $12.466 / 2011^{4}$ que determinam que a partilha dos recursos federais entre os estados deve ser pactuada no âmbito da CIT, o que evidencia a institucionalidade da participação das subunidades governamentais nas decisões relacionadas ao financiamento da política - aspecto não observado no caso da política de assistência social -, e que justifica o grande número de decisões sobre financiamento.

Os dados sobre o padrão das relações entre os entes federados demonstram haver traços de concentração, que favorecem o nível federal, mas que as subunidades governamentais fazem valer, de forma mais contundente do que no caso da política de assistência social, seus respectivos poderes de influência sobre as decisões. Isso pode ser evidenciado pelas características da participação dos níveis de governo nas decisões relativas à implementação da política no âmbito regional (o que agrega novas decisões num processo constante de formulação em processo); e pela distribuição geral dos esultados das deliberações, bem como quando o nível federal de governo é o proponente.

\footnotetext{
3"Art. 32. As Comissões Intergestores pactuarão: I - aspectos operacionais, financeiros e administrativos da gestão compartilhada do SUS (...). Parágrafo único. Serão de competência exclusiva da CIT a pactuação: (...) III - das diretrizes nacionais, do financiamento e das questões operacionais das Regiões de Saúde situadas em fronteiras com outros países (...)".

4"Art. 14-A. As Comissões Intergestores Bipartite e Tripartite são reconhecidas como foros de negociação e pactuação entre gestores (...). Parágrafo único. A atuação das Comissões Intergestores Bipartite e Tripartite terá por objetivo: I - decidir sobre os aspectos operacionais, financeiros e administrativos da gestão compartilhada do SUS (...)".
} 
Gráfico 03 - Tipos de participação (\%) de cada nível de governo nas deliberações pactuadas no âmbito da CIT da Política de Saúde (2009-2012)

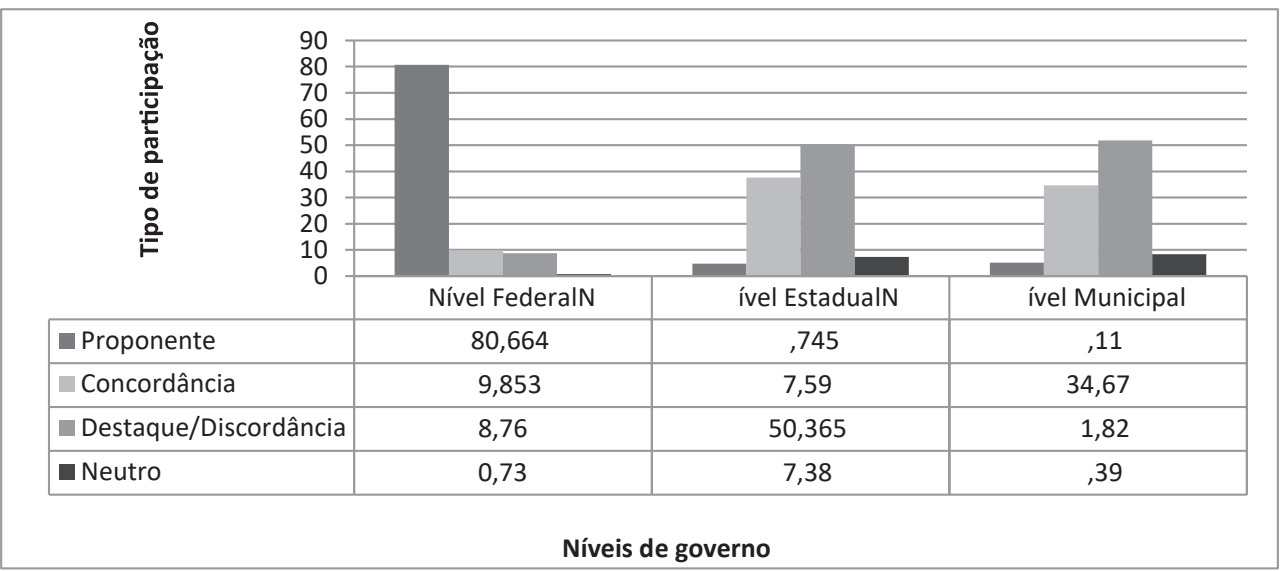

Fonte: elaboração própria a partir das atas da CIT da Política de Saúde (2009-2012).

Como pode ser percebido, o nível federal também nesta CIT é o principal proponente das matérias sobre as quais se delibera. Mas, diferente do que ocorre na CIT da Assistência Social, não há, por parte do mesmo, um percentual considerável de intervenções no sentido de explicitar adequações e mudanças (destaques) ou discordar de traços das propostas (nas situações em que alguns aspectos são passados para reuniões futuras). As características de participação dos representantes dos níveis estadual e municipal de governo são similares àquelas que identificamos na CIT da Assistência Social, ou seja, conjugam o endossamento das matérias (com um percentual ligeiramente mais elevado do que no caso da assistência social), com a apresentação de destaques sobre adequações e discordâncias. Mas, a maior frequência percentual é também - como no caso da assistência social - dos destaques e posições de desacordo, que se constituem como a principal característica de participação das subunidades governamentais.

Esse resultado expressa o papel de coordenação da política de saúde pelo nível federal de governo, que detém recursos institucionais para isso-poder normatizador e maior volume de recursos (responsável por aproximadamente $45 \%$ do gasto total com ações e serviços de saúde, conforme Menicucci, 2014) -, o que lhe permite induzir as escolhas e obter adesões dos outros entes federados. Ainda assim existe considerável força dos níveis subnacionais de governo nas decisões sobre as ações produzidas sobre o setor no âmbito da CIT, quando os mesmos exercem sua forma de atuação predominante, que é de apresentar destaques e posições de desacordo às propostas, conforme visualizado no Gráfico 04 . 
Gráfico 04 - Resultados das deliberações (\%) em geral e quando o nível federal atuou como proponente nas reuniões da CIT da Saúde (2009-2012)

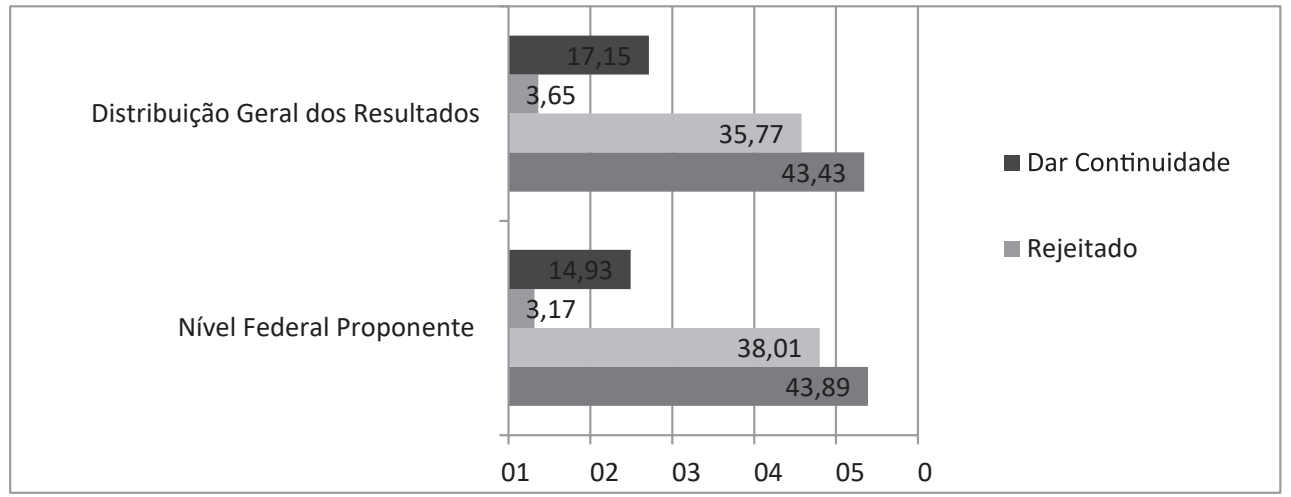

Fonte: elaboração própria a partir das atas da CIT da Política de Saúde (2009-2012).

A distribuição geral dos resultados das deliberações é muito semelhante ao da situação em que o nível federal de governo é o proponente, o que ocorreu em mais de $80 \%$ das situações. Embora também seja alto o percentual de pactuações das matérias tal como propostas, ele é seguido de perto pelas pactuações que ocorreram após ajustes e adequações, podendo-se falar em um equilíbrio entre decisões que seguem sem restrições as propostas federais e as que incorporam alterações. Ressalte-se ainda que um percentual significativo (próximo de 20\%) aponta para não aprovação de propostas, seja por adiamento da decisão seja por rejeição, o que sugere um papel ativo dos entes subnacionais.

Em síntese, nessa instância decisória há maior equilíbrio entre as deliberações sobre questões relacionadas à gestão das ações e as deliberações sobre aspectos financeiros, decidindo-se também sobre aspectos estruturais do financiamento, como os limites financeiros relativos ao custeio de procedimentos de média e alta complexidade ambulatorial e hospitalar por parte dos estados; o financiamento dos laboratórios de referência da vigilância sanitária, das ações de controle epidemiológico e da assistência farmacêutica. Embora o maior poder do nível federal seja também uma característica evidente, parece haver significativa influência sobre as decisões por parte dos estados e municípios.

\section{Conclusões}

Este artigo teve como objetivo analisar de forma comparada o padrão da produção de decisões intergovernamentais verticais, entre os três níveis de governo, no âmbito das políticas nacionais de saúde e assistência social tomando como unidade de análise as Comissões Intergestores Tripartite, vistas como arenas 
federativas para pactuação e produção de decisões conjuntas e similares no arranjo institucional das duas políticas. O pano de fundo dessa análise é a noção de governança federativa, como uma forma de governança pública, entendida como as interações intergovernamentais para a busca de melhores resultados da atuação governamental em contexto federativo nos quais a conjugação de autonomia e interdependência dos entes federados envolve negociação e comunicação entre eles, devendo as políticas públicas ser negociadas e barganhadas. Nas CITs são produzidos acordos e decisões fora das instituições centrais do governo nacional num processo de descentralização e desierarquização dos processos decisórios, remetendo à essência da ideia de governança que denota pluralismo, no sentido que diferentes atores - no caso os entes federados - têm o direito de influenciar a construção das políticas públicas em processos decisórios conjuntos decorrentes do fato de a autoridade e a responsabilidade sobre as políticas ser partilhada entre múltiplas jurisdições. No caso das políticas de saúde e assistência social no Brasil, foram definidas competências comuns aos três entes, o que remete à necessidade de uma governança compartilhada, sendo as comissões intergestores instâncias para favorecer a interação, as pactuações e decisões ao estabelecer centros múltiplos de elaboração da política pública, em nível nacional (CIT), estadual (CIB) e regional (CIR).

Focando apenas nas CITs, a análise da produção de decisões apontou similaridades entre as duas políticas e pontos divergentes no que diz respeito às características das deliberações, tanto no que diz respeito aos aspectos deliberados, quanto em relação ao tipo de participação e influência dos níveis governamentais na produção das decisões.

Nos dois casos existe alta concentração de deliberações sobre questões relacionadas aos serviços - serviços de assistência social e assistência à saúde -, o que se justifica em alguma medida por serem estes os aspectos centrais das duas políticas. No caso da assistência social, as outras partes constituintes da política, especificamente os benefícios de renda, apresentam baixos percentuais na distribuição das questões deliberadas na CIT, o que parece decorrer de um processo ainda não resolvido de acomodação das intervenções e instituições forjadas ao longo da trajetória da política. Tanto a gestão do Programa Bolsa Família quanto a do Benefício de Prestação Continuada estão sob a responsabilidade de agências específicas distintas daquelas responsáveis pela gestão estrito-sensu do Suas, ou seja, há baixa integração entre os serviços e benefícios, esses sendo objeto de decisões externas à CIT e bastante centralizadas, sugerindo uma estrutura de governança hierarquizada que passa ao largo das deliberações da CIT. Diferentemente, no caso da política de saúde, todas as ações e serviços no 
escopo de atuação do SUS são objeto de deliberações, tanto sobre aspectos referentes à gestão quanto ao financiamento, ainda que com uma distribuição percentual desequilibrada em relação aos serviços - justificado pelo peso dessas ações no âmbito do SUS, que se propõe a garantir assistência à saúde a todos os cidadãos em todo o território nacional.

Uma diferença entre a dinâmica decisória das duas comissões refere-se aos aspectos que são prioritariamente objeto de deliberação. Embora as deliberações referentes à gestão sejam predominantes nos dois casos, isso é mais proeminente na assistência social, ao passo que na saúde as decisões referentes ao financiamento são significativas. Isso expressa tanto a centralidade do debate sobre a insuficiência dos recursos no setor quanto o imperativo de definição dos fluxos financeiros e da partilha dos recursos federais entre os estados que deve ser pactuada no âmbito da CIT, o que institucionaliza a participação das subunidades governamentais nas decisões relacionadas ao financiamento da política de saúde.

Conforme esperado, tendo em vista o poder institucional da União nas duas políticas, o nível federal ocupa posição preponderante na proposição das matérias deliberadas na CIT nos dois casos, cabendo aos níveis estadual e municipal a presentar propostas de ajustes ou discordância completa sobre os temas. Apesar de pouco propositivos, os entes subnacionais têm atuação importante como pontos de veto, adiando decisões, alterando as propostas originais ou mesmo não aprovando as propostas. A centralização das proposições no nível federal pode ser justificada pela macro estrutura institucional do país, que favorece a concentração dos poderes no nível federal e, particularmente, por sua função de normatização e coordenação nacional das políticas de saúde e assistência social.

Por fim, o fato de se tratar de comissões voltadas à produção de decisões intergovernamentais sobre as políticas não garante que todos os elementos constitutivos das políticas serão realmente debatidos e decididos em seu interior de forma balanceada. Além disso, a garantia institucional de participação das subunidades governamentais não assegura uma condição de igualdade de poder nos processos de deliberação. Entretanto, sua influência não pode ser negligenciada e precisa ser considerada no jogo decisório no processo de construção de uma governança federativa.

Efetivamente, por meio das CITs, os vários entes federados participam do processo de produção de decisões e de gestão da política de saúde e da assistência social. A partir da coordenação exercida pelo ente federal, esse mecanismo institucional pode ser visto como uma arena federativa que favorece a cooperação por meio de negociação e barganha. Essa estrutura de governança tem como traço distintivo a dimensão relacional e a descentralização do processo decisório e da ação pública para fora dos limites das instituições formais do governo nacional, produzindo um 
desenho complexo das políticas de forma a incorporar as necessidades e interesses de cada ente, numa situação em que constitucionalmente as responsabilidades são compartilhas entre as três esferas da federação e a ação interdependente entre elas é essencial para a condução das duas políticas.

\section{Referências bibliográficas}

ABRUCIO, Fernando Luiz. A Coordenação Federativa no Brasil: a experiência do Período FHC e os desafios do Governo Lula. Rev. Sociol. \& Polít. Curitiba, 24, p. 41-67, jun. 2005. ARRETCHE, Marta Teresa da Silva. Democracia, federalismo e centralização no Brasil. Rio de Janeiro: Editora FGV e Fiocruz, 2012. 232p.

ARRetChe, Marta Teresa da Silva. Estado federativo e políticas Sociais: determinantes da descentralização. Rio de Janeiro: Renavan, São Paulo: Fapesp, 2000. 304p.

ARRETCHE, Marta Teresa da Silva. Federalismo e democracia no Brasil. A visão da Ciência Política norte-americana. São Paulo em Perspectiva, v.15, n. 4, 2001.

ARRETCHE, Marta Teresa da Silva. Federalismo e igualdade territorial: uma contradição em termos? 34 Encontro Anual da ANPOCS. Caxambu, outubro de 2010.

ARRETCHE, Marta Teresa da Silva. Federalismo e relações intergovernamentais no Brasil: a reforma de programas sociais. Revista de Ciências Sociais, Rio de Janeiro, v. 45, n. 3, p.431 a 458, 2002a.

ARRETCHe, Marta Teresa da Silva. Financiamento federal e gestão local de políticas sociais: o difícil equilíbrio entre regulação, responsabilidade e autonomia. Ciência e Saúde Coletiva, v. 8, n. 2,p. 331-345, 2003.

Arretche, Marta Teresa da Silva. Relações Federativas nas Políticas Sociais. Educ. Soc., Campinas, v. 23, n. 80, p. 25-48, setembro/2002b.

BRASIL. Constituição de 1988. Brasília: Senado Federal. Subsecretaria de Edições Técnicas, 1999. XIV, 360p.

BRASIL. Política Nacional de Assistência Social/2004 e NOB/SUAS/2005, Brasília, nov.2005.

BRASIL. Presidência da República, Casa Civil, Subchefia para Assuntos Jurídicos. Lei $n$ ㅇ 8.742 de dezembro de 1993.

BRASIL. Presidência da República, Casa Civil, Subchefia para Assuntos Jurídicos. Decreto no 7.508, de 28 de junho de 2011.

BRASIL. Presidência da República, Casa Civil, Subchefia para Assuntos Jurídicos. Lei no 12.466, de 24 de agosto de 2011.

BRASIL. Presidência da República, Casa Civil, Subchefia para Assuntos Jurídicos. Lei no 8.080, de 19 de setembro de 1990.

BRASIL. Presidência da República, Casa Civil, Subchefia para Assuntos Jurídicos. Lei no 8.142, de 28 de dezembro de 1990.

BRASIL. Presidência da República, Casa Civil, Subchefia para Assuntos Jurídicos. Lei no 8.742, de 07 de dezembro de 1993. 
BRASIL. Presidência da República, Casa Civil, Subchefia para Assuntos Jurídicos. Lei no 9.665, de 19 de junho de 1998.

BRASIL. Presidência da República, Casa Civil, Subchefia para Assuntos Jurídicos. Lei no 12.435, de 06 de julho de 2011.

BRASIL. Resolução CNAS no 33 de 12 de dezembro de 2012. Norma Operacional Básica/SUAS 2012.

COSTA, Valeriano Mendes Ferreira. Relações intergovernamentais no Brasil: desenvolvimentos recentes e perspectivas. Forum of federations, 2003.

FONTES FILHO, Joaquim R. Governança organizacional aplicada ao setor público. VIII Congreso Internacional del CLAD sobre la Reforma del Estado y de la Administración Pública, Panamá, 2003.

GontıJo, José Geraldo Leandro. Coordenação, cooperação e políticas públicas: organizando percepções e conceitos sobre um tema caro à implementação. In: FARIA, Carlos Aurélio Pimenta de. Implementação de Políticas Públicas: teoria e prática. Belo Horizonte: Ed. PUC Minas, 2012.

Instituto de Pesquisa Econômica Aplicada (IPEA). Políticas sociais: acompanhamento e análise, v. 23. Brasília: Ipea, 2015.

LOWNDES, Vivien; SKELCHER, Cris. The dynamics of multi-organizational partnerships: an analysis of changing modes of governance. Public Administration, Malden, v. 76, n. 2, p. 313333, Summer 1998.

KISSLER, Leo; HEIDEMANN, Leo. Governança pública: novo modelo regulatório para as relações entre Estado, mercado e sociedade? RAP, Rio de Janeiro, v. 40, n. 3p. 479-99, maio/jun. 2006. MACHADO, José Ângelo. Gestão de políticas públicas no Estado federativo: apostas e armadilhas. Revista de Ciências Sociais, Rio de Janeiro, v. 51, n. 2 ,, p. $433-457,2008$.

MENICUCCI, Telma Maria Gonçalves. A relação entre o público e o privado e o contexto federativo do SUS. Uma análise institucional. Santiago: Cepal. Série Políticas Sociais, v. 196, junho de 2014.

MenICuCCI, Telma; GontIJo, José Geraldo L. Apresentação. In: MENICUCCI; GoMIDE (org.) Gestão e políticas públicas no cenário contemporâneo - tendências nacionais e internacionais. Rio de Janeiro: Fiocruz, 2016, p.15-35.

Menicucci, Telma; D’Albuquerque, Raquel. Política de saneamento vis-à-vis à política de saúde: encontros, desencontros e seus efeitos. In: HELLER, Léo (org.). Saneamento como política pública: um olhar a partir dos desafios do SUS. Rio de Janeiro: Centro de Estudos Estratégicos da Fiocruz/Fiocruz, 2018. Disponível em: http://cee.fiocruz.br/sites/default/files/2_Leo\%20Heller\%20et\%20al_ saneamento.pdf

PIRES, Roberto R.C.; GOMIDE, Alexandre de A. Governança, arranjos institucionais e capacidades estatais na implementação de políticas públicas. In: MENICUCCI; GOMIDE (org.) Gestão e Políticas Públicas no cenário contemporâneo - tendências nacionais e internacionais. Rio de Janeiro: Fiocruz, 2016, p.101-130. 
PIRES, Maria C. S. Federalismo brasileiro: a emergência de um redesenho institucional do modelo. Revista Brasileira de Estudos Políticos. Belo Horizonte. n. 106 | p. 163189 | jan./jun. 2013.

PIERSON, Paul. Fragmented Welfare States: federal institutions and the development of Social Policy. Governance. V. 8, n. 4, p.449-478, out. 1995.

RICHARDS, D. Smith, M.J. Governance and public policy in the United Kingdom. New York: Oxford University Press, 2002.

SECHI, Leonardo. Modelos organizacionais e reformas da administração pública. RAP, Rio de Janeiro, v. 43, n. 2, p. 347-69, mar./abr. 2009.

Silva, Flávia de Araújo; MARTINS, Túlio C. P. M.; CKAgnAZARoff, Ivan Beck. Revista do Serviço Público. Brasília, v. 64, n. 2, p. 249-271, abr/jun 2013.

SOARES, M. M. Repasses financeiros e voluntários da União aos municípios brasileiros: condicionantes políticos, sociais e técnicos. 8o Encontro da $A B C P, 01$ a 04 de agosto, 2012.

SouzA, Celina. Condições institucionais de cooperação na região metropolitana de Salvador. In: SouzA, Celina. Federalismo e gasto social no Brasil: tensões e tendências. Lua Nova. no 52, 2001.

Federalismo, Desenho Constitucional e Instituições Federativas no Brasil Pós-1988. Rev. Sociol. Polít., Curitiba, 24, p. 105-121, jun/2005.

Federalismo e políticas públicas nacionais: diversidade ou uniformidade? In: MeNicuCCI; GoMide (org.) Gestão e Políticas Públicas no cenário contemporâneo - tendências nacionais e internacionais. Rio de Janeiro: Fiocruz, 2016, p.131-154.

VIANA, Ana Luiza D’ávila; LIMA, Luciana Dias de; OLIVEIRA, Roberta Gondoim de. Descentralização e federalismo: a política de saúde em novo contexto - lições do caso brasileiro. In: Ciência da Saúde Coletiva.v.7, n. 3, Rio de Janeiro, 2002.

José Geraldo Leandro

Doutor em Ciência Política pela Universidade Federal de Minas Gerais (UFMG). Atualmente, realiza pós-doutorado no Departamento de Ciência Política da UFMG, onde também é professor residente e pesquisador vinculado ao Núcleo de Estudos em Gestão e Políticas Públicas (Publicus).Contato: josegleandro@ig.com.br

Telma Maria Gonçalves Menicucci

Doutora em Sociologia e Política pela Universidade Federal de Minas Gerais (UFMG). Atualmente é professora adjunta do Departamento de Ciência Política da UFMG e coordenadora do Núcleo de Estudos em Gestão e Políticas Públicas (Publicus). Contato: tgmenicucci@gmail.com 